\title{
Objective Evaluation of the Longevity of A Calcium Hydroxylapatite-Based Filler (Radiesse ${ }^{\circledR}$ )
}

\author{
Maria Angelo-Khattar* \\ Overseas Director, American Academy of Anti-aging Medicine, Dubai, UAE
}

*Corresponding author: Maria Angelo-Khattar, Overseas Director, American Academy of Anti-aging Medicine, Dubai, UAE, Tel: 971506245494; E-mail: mkhattar@younatagroup.com

Received: 19 Apr, 2021 | Accepted: 15 May, 2021 | Published: 22 May, 2021

Citation: Angelo-Khattar M (2021) Objective Evaluation of the Longevity of A Calcium Hydroxylapatite-Based Filler (Radiesse $\left.{ }^{\circledR}\right)$. J Clin Cosmet Dermatol 5(2): dx.doi.org/10.16966/2576-2826.163

Copyright: (C) 2021 Angelo-Khattar M. This is an open-access article distributed under the terms of the Creative Commons Attribution License, which permits unrestricted use, distribution, and reproduction in any medium, provided the original author and source are credited.

\begin{abstract}
Background: Calcium hydroxylapatite (CaHA) based soft-tissue filler (Radiesse ${ }^{\circ}, \mathrm{Merz}$ ) is categorised as a biodegradable collagen-stimulating implant. It is comprised of a suspension of $25-45$ micron diameter microspheres of $\mathrm{CaHA}(30 \%)$ in a carboxymethylcellulose (CMC) gel carrier (70\%) and is one of the most well researched soft-tissue fillers. However, great discrepancies exist in the literature regarding the duration of clinical effect with the implant, ranging from only 6 to 24 months.
\end{abstract}

Objective: This is a retrospective chart analysis of four patients injected with CaHA filler for volume augmentation in the malar region of the face. Objective volume calculations were performed with the Canfield Vectra 3D Imaging System three and five months post-implantation, with the view to determine the longevity of the volumizing effect of the filler substance.

Discussion: CaHA based filler is believed to afford immediate volume restoration due to the CMC gel component and a long-term action due to neocollagenesis induced by the CaHA microspheres. The CMC gel is known to dissipate within 6-8 weeks, only to be replaced by new collagen induced by the CaHA particles. Thus soft-tissue formation is believed to lead to a sustained volumizing effect.

Results of this retrospective study clearly show that the volume replacement afforded by the filler was not sustained, with $65 \%$ and up to $96 \%$ reduction in volume at five months.

Conclusion: The volumizing effect of CaHA based filler is shown to have limited longevity, despite the fact that it is a proven biostimulant. It is possible that the CaHA microspheres are degraded relatively swiftly in interstitial fluid and therefore cannot sustain their biostimulating effect.

Keywords: Calcium hydrxylapatite; Radiesse ; Biostimulant; Poly-L-lactic acid; Vectra 3D

\section{Introduction}

Soft tissue fillers, originally developed for the filling of rhytids and folds, are currently used for the global restoration of facial volume and optimization of facial contours as in chin, tear trough, cheek, lip, and jawline correction. Recently several fillers have proven to be of value in the correction of non-facial areas. They are of great benefit in hand rejuvenation, rejuvenation of the décolleté and neck, reduction of cellulite dimpling, buttock augmentation, volumizing of the labia majoré, and post-liposuction deformity correction $[1,2]$.

The current plethora of soft-tissue filler substances essentially comprises three general categories; the replacement biodegradable fillers (Hyaluronic acid products), the permanent non-biodegradable fillers (ex. Polymethylmethacrylate, polyacrylamide gel, silicone), and biodegradable collagen-stimulating substances. There is no doubt that hyaluronans are the most widely used soft-tissue fillers worldwide $[3,4]$. This is despite the fact that they have limited longevity, between 6-12 months, since they are metabolized by endogenous hyaluronidase enzymes. The hyaluronic acid filler's longevity depends upon the extent of cross-linkage and the concentration and particle size of each product. These medical devices are replacement fillers and simply restore lost volume but do not induce long-term collagenstimulating effects $[5,6]$.

The non-biodegradable products are generally not approved in most countries as they are associated with severe side effects and persistent granulomas that can occur several years after implantation [4].

The quest for longer-lasting biodegradable substances has resulted in the development of substances that provide longer-term correction by inducing new soft tissue formation. This category of biodegradable collagen-stimulating substances includes three types of implantable medical devices; poly-l-lactic acid (PLLA), calcium hydroxyapatite (CaHA), and polycaprolactone-based fillers. Typically, these are 
particulate substances between 25 to 45 microns in size that illicit an inflammatory reaction resulting in encapsulation of the particles and the prevention of particle migration. They ultimately lead to neocollagenesis, and the induction of new soft tissue formation by these biostimulating substances results in long-lasting cosmetic correction, in certain cases persisting well over two years $[7,8]$.

CaHA-based filler (Radiesse, Merz) is comprised of a suspension of CaHA microsphere ranging from 25 to 45 micron in diameter, in a carboxymethyl cellulose gel carrier [9]. It is one of the most extensively studied fillers currently used for soft tissue augmentation. However, great discrepancies exist in the literature regarding the duration of clinical effect with the implant, ranging anywhere from only 6 months to 24 months [9-13]. The vast majority of these studies have employed subjective evaluation scales such as the global aesthetic improvement scale and the wrinkle severity rating scale, which rely on the investigator's and patient's evaluation of the results.

A review of the literature revealed only one objective study whereby 3D surface scanning was employed for the quantification of soft tissue changes in three female subjects treated with CaHA filler. Volume quantifications were made immediately post injection, 2 weeks and six months after injection with an Artec MHT surface scanner (Artec Group, San Diego, California). The authors concluded that the filler persisted for six months after treatment. However qualitative data from the colour coding of the heat maps showed a clear decline in volume at six months [14].

Three-dimensional (3D) imaging systems for the face and body are currently employed for surgical planning and research. The Canfield 3D stereophotogrammetric camera and software (Vectra; Canfield Scientific, Fairfield, NJ) is being increasingly used in computerized volume calculations post filler injections, breast augmentation and cryolipolysis [15-18]. The system has been shown to be reliable and reproducible and the $3 \mathrm{D}$ imaging system measurements show a linear association with Magnetic Resonance Imaging [19].

\section{Materials and Methods}

This is a retrospective chart review of four female subjects, aged 28-50 years, treated with CaHA filler on the malar area of the face, between january to june 2015 . The subjects retrospectively studied were randomly selected. Ethical approval to analyse the patient data retrospectively was awarded by the Clinic Director based on consent given by the patients to analyse and publish the data (Figure 1).

\section{Injection technique}

In our clinics, all patients that receive filler injections in the infraorbital area are pre-treated with an infraorbital block $(2 \%$ xylocaine+1:80,000 adrenaline). The CaHA filler is then injected onto the supra-periosteal plane in the malar area on both sides of the face, with a $22 \mathrm{G} \times 50 \mathrm{~mm}$ blunt-tipped cannula.

\section{Imaging}

The Vectra 3D Imaging system (Canfield Imaging Systems, Fairfield, N.J) is used as part of standard of care in our clinics. The system contains six cameras and captures images in 180 degrees. Standardized full face 2D and 3D images are generated. The high resolution $3 \mathrm{D}$ images produced by the Vectra software can be used for both qualitative volume visualisation and quantitative volume measurements.

Standardized full-face 2D and 3D digital surface imaging were taken of the four patients at baseline and then at 3 months and 5 months after the injection session. Data from the four patients were analysed by importing the baseline and the 3 and 5 month images into the Vectra mirror analysis $3 \mathrm{D}$ software. The mid-face region was selected in each case and highlighted as the area to be measured. Change in mid-face volume was computed by registering each the post-treatment images against the baseline image. All volume measurements were recorded in millilitres.

Furthermore, qualitative volume visualization of the degree of contour change was made possible with a colour distance map (See figure 2).

\section{Results \\ Qualitative data}

Figure 2 is representative of colour distance maps indicating a qualitative change in volume over time. The colour scale is shown whereby green is baseline and any increase in volume manifests incrementally as yellow and red.

Figure 2 represents a 45 -year-old patient who had been injected with a total of $1.5 \mathrm{ml}$ of CaHA filler on both malar areas. The yellow and intense red colours are indicative of volume increase from baseline, seen at one month post treatment. The decline in colour intensity at the fifth month is a clear indication that the volume was not sustained.

\section{Quantitative data}

Table 1 shows the volume of CaHA filler injected on each side of the face and the total volume, for each of the patients. The volume remaining at 3 months and 5 months are also shown. The residual volume at 5 months, computed as a percentage of total filler remaining, was only a fraction of the original volume, between $4 \%$ and $35 \%$.

\section{Discussion}

The CaHA-based filler has gained great popularity as both a volumizing agent and a treatment modality for skin rejuvenation in non-facial skin such as on the neck, decolletage, inner arms, and hands. In certain cases, the bio-stimulant is used concomitantly with microfocused ultrasound for optimal effects [20-24].

The mechanism of action of the soft-tissue filler ultimately depends upon the activation of fibroblasts by the CaHA microspheres to elicit collagen production. Histological and electron microscopic studies in human volunteers have demonstrated new collagen deposition around the microspheres for up to six months $[25,26]$. Immunohistochemical analysis $[23,25]$ demonstrated a significant increase in both collagen type I and type III at 4 and 7 months post-treatment. A more recent study using picrosirius red staining and polarized light microscopy, 2 months after implantation, mainly newly formed type III collagen was identified [27]. Hence, there is no doubt that CaHA in a collagen stimulating agent. Nonetheless, several studies have demonstrated limited clinical efficacy [14] with the filler and, our results using quantitative Vectra 3D evaluation have also shown a clear decline in volume over five months. Hence it may be concluded that the collagen stimulating effects of the CaHA filler are not long-lasting.

Data from studies on the longevity of another collagen stimulating agents, Poly-L-Lactic acid (PLLA), shows that in contrast to CaHA filler, the volumizing action of PLLA is between 2 to 3 years [28-32].

PLLA is a biodegradeable and biocompatible polyhydroxyacid that does not augment the skin directly but has an indirect effect due to neocollagenesis [33]. When injected into the tissue, the particles of PLLA degrade over time, only to be replaced by the patients' own collagen, a process that persists for up to 25 months [34,35]. 


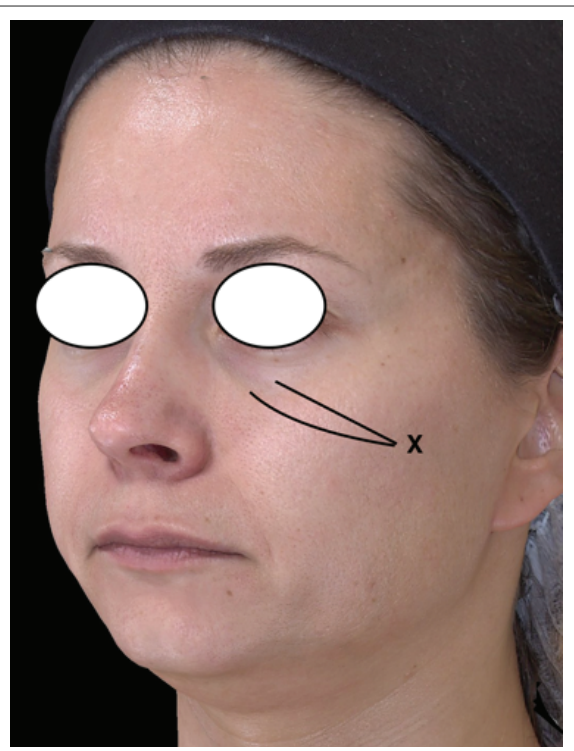

Figure 1: Site of injection of Calcium hydroxylapatite filler in the mid face. A $22 \mathrm{G}, 50 \mathrm{~mm}$ length cannula was inserted at point $\mathrm{X}$ on the zygomatic arch and the filler was deposited on the supraperiosteal plane.

Baseline image
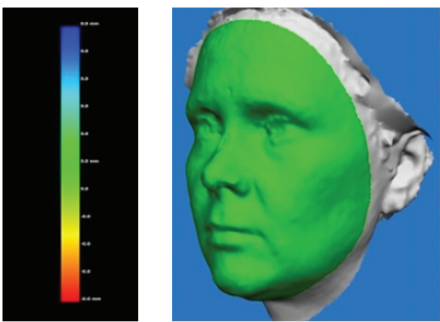

Baseline image

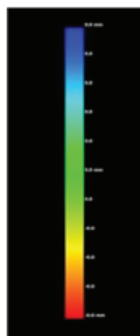

Post 1 month
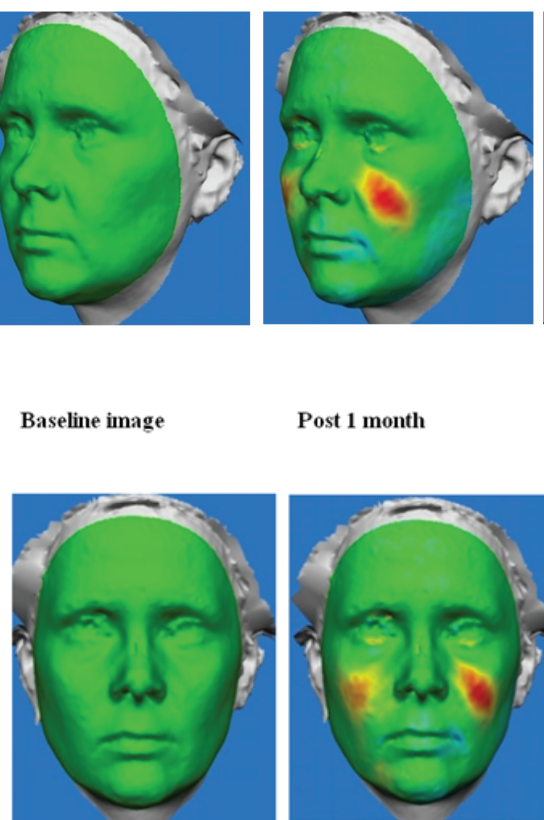

Post 1 month

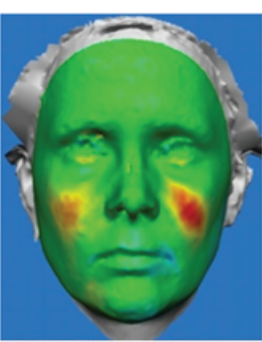

Post 5 months
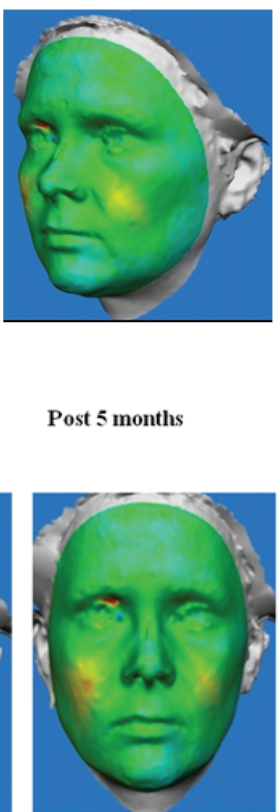

Figure 2: Frontal and profile colour distance maps of 45-year old patient injected with a total volume of $1.5 \mathrm{cc}$ of CaHA filler both malar areas.

Table 1: The volume of CaHA filler injected on each side of the face and the total volume for each of the patients.

\begin{tabular}{|l|c|c|c|c|c|c|c|}
\hline Patient & $\begin{array}{c}\text { Volume CaHA filler } \\
\text { injected on right side } \\
\text { (cc) }\end{array}$ & $\begin{array}{c}\text { Volume } \\
\text { CaHA filler injected } \\
\text { on left side }\end{array}$ & $\begin{array}{c}\text { Total Volume CaHA } \\
\text { filler injected }\end{array}$ & $\begin{array}{c}\text { Total Volume at } \\
\text { 3 months }\end{array}$ & $\begin{array}{c}\text { Total Volume at } \\
\text { 5 months }\end{array}$ & $\begin{array}{c}\text { \% Residual } \\
\text { volume at 5 } \\
\text { months }\end{array}$ & $\begin{array}{c}\text { \% Decrease in } \\
\text { volume at 5 } \\
\text { months }\end{array}$ \\
\hline AP & 0.45 & 0.35 & 0.80 & 0.39 & 0.02 & 4 & 96 \\
\hline GE & 0.35 & 0.45 & 0.80 & 0.20 & 0.06 & 7.5 & 92.5 \\
\hline JK & 0.55 & 0.45 & 1.00 & 0.49 & 0.35 & 35.0 & 65 \\
\hline KK & 0.40 & 0.30 & 0.70 & 0.24 & 0.07 & 10 & 90 \\
\hline
\end{tabular}


A study using 3-D digital imaging showed that subjects treated with PLLA had significant increases from baseline in mid-face volume at the end of the trial, six months after the first injection session [36].

Over 29 types of collagen are present in the human body with types I and III being predominantly found in the skin. The collagen fibres, which are the most abundant components of the extracellular matrix, are of high tensile strength and impart strength and resilence to the skin [37].The efficacy of biostimulating agents in inducing neocollagenesis and new soft tissue formation is contingent upon on the persistence of the biostimulant in the tissue to allow for long-term fibroblast stimulation.

Hence, the limited volumizing action of CaHA may be explained by the limited longevity of the microspheres in the body, possibly due to the swift degradation of the CaHA microspheres in interstitial fluid.

\section{Conclusion}

Calcium hydroxylapatite soft tissue filler is a proven biostimulant. However, objective volume assessments performed with the Canfield Vectra 3D analysis system, showed that the volume augmentation with the filler is not sustained but on the contrary, a significant decline is seen within five months of injection.

\section{Disclosure}

The author reports no conflicts of interest in this work.

\section{References}

1. Goldberg DJ, Bass LM, Fitzgerald R, Graivier MH, Lorenc ZP (2018) Expanding Treatment Options for Injectable Agents. Aesthet Surg J 38: S1-S7.

2. Jabbar A, Arruda S, Sadick N (2017) Off Face Usage of Poly-L-Lactic Acid for Body Rejuvenation. J Drugs Dermatol 16: 489-494.

3. Rohrich RJ, Bartlett EL, Dayan E (2019) Practical Approach and Safety of Hyaluronic Acid Fillers. Plast Reconstr Surg Glob Open 7: e2172.

4. Funt D, Pavicic T (2013) Dermal fillers in aesthetics: an overview of adverse events and treatment approaches. Clin Cosmet Investig Dermatol 6: 295-316.

5. Keen MA (2017) Hyaluronic Acid in Dermatology. 15: 441-448.

6. Lee W, Hwang SG, Oh W, Kim CY, Lee JL, et al. (2020) Practical Guidelines for Hyaluronic Acid Soft-Tissue Filler Use in Facial Rejuvenation. Dermatol Surg 46: 41-49.

7. Breithaupt A, Fitzgerald R (2015) Collagen Stimulators: Poly-L-Lactic Acid and Calcium Hydroxyl Apatite. Facial Plast SurgClin North Am 23: 459-469.

8. Melo FD, Nicolau P, Piovano L, Lin SL, Fernandes TB, et al. (2017) Recommendations for volume augmentation and rejuvenation of the face and hands with the new generation polycaprolactonebased collagen stimulator (Ellansé ${ }^{\circ}$. Clin Cosmet Investig Dermatol 10: 431-440.

9. Loghem JV, Yutskovskaya YA, Werschler WP (2015) Calcium hydroxylapatite: over a decade of clinical experience. J Clin Aesthet Dermatol 8: 38-49.

10. Emer J, Sundaram H (2013) Aesthetic applications of calcium hydroxylapatite volumizing filler: an evidence-based review and discussion of current concepts: (part 1 of 2). J Drugs Dermatol 12: 1345-1354.
11. Tzikas TL (2008) A 52-month summary of results using calcium hydroxylapatite for facial soft tissue augmentation. Dermatol Surg 34 Suppl 1: S9-S15.

12. Sadick SN, Katz EB, Roy D (2007) A multicenter, 47-month study of safety and efficacy of calcium hydroxylapatite for soft tissue augmentation of nasolabial folds and other areas of the face. Dermatol Surg 33: S122-S126.

13. Jacovella PF (2008) Use of calcium hydroxylapatite (Radiesse') for facial augmentation. Clin Interv Aging 3: 161-174.

14. Simunovic F, Schlager S, Montanari M, Iblher N (2017) Prospective $3 \mathrm{D}$ analysis of facial soft tissue augmentation with calcium hydroxylapatite. J Cosmet Laser Ther 19: 283-289.

15. Lowe P, Lowe NJ, Patnaik R (2011) Three-dimensional digital surface imaging measurement of the volumizing effect of injectable poly-Llactic acid for nasolabial folds. J Cosmet Laser Ther 13: 87-94.

16. Killaars RC, Preuß MLG, de Vos NJP, Van Berlo CCJLY, Lobbes MBI, et al. (2020) Clinical Assessment of Breast Volume: Can 3D Imaging Be the Gold Standard? last Reconstr Surg Glob Open 8: e3236.

17. Garibyan L, Sipprell WH, Jalian HR, Sakamoto FH, Avram M, et al. (2014) Three-dimensional volumetric quantification of fat loss following cryolipolysis. Lasers Surg Med 46: 75-80.

18. Landau MJ, Kim JS, Gould DJ, Patel KM (2018) Vectra 3D Imaging for Quantitative Volumetric Analysis of the Upper Limb: A Feasibility Study for Tracking Outcomes of Lymphedema Treatment. Plast Reconstr Surg 141: 80e-84e.

19. De Menzes M, Rosati R, Ferrario VF, Sforza C (2010) Accuracy and reproducibility of a 3-dimensional stereophotogrammetric imaging system. J Oral Maxillofac Surg 68: 2129-2135.

20. Amselam M (2015) Radiesse $e^{\left({ }^{\circ}\right.}$ : a novel rejuvenation treatment for the upper arms. Clin Cosmet Investig Dermatol 9: 9-14.

21. De Almeida AT, Figueredo V, Da Cunha ALG, Casabona G, De Faria JRC, et al. (2019) Consensus Recommendations for the Use of Hyperdiluted Calcium Hydroxyapatite (Radiesse) as a Face and Body Biostimulatory Agent. Plast Reconstr Surg Glob Open 7: e2160.

22. Casabona G, Marchese P (2017) Calcium Hydroxylapatite Combined with Microneedling and Ascorbic Acid is Effective for Treating Stretch Marks. Plast Reconstr Surg Glob Open 5: e1474.

23. Yutskovskaya YA, Kogan EA (2017) Improved Neocollagenesis and Skin Mechanical Properties After Injection of Diluted Calcium Hydroxylapatite in the Neck and Décolletage: A Pilot Study. J Drugs Dermatol 16: 68-74.

24. Casabona G, Teixeira DN (2018) Microfocused ultrasound in combination with diluted calcium hydroxylapatite for improving skin laxity and the appearance of lines in the neck and décolletage. J Cosmet Dermatol 17: 66-72.

25. Berlin AL, Hussain M, Goldberg DJ (2008) Calcium hydroxylapatite filler for facial rejuvenation: a histologic and immunohistochemical analysis. Dermatol Surg 34: S64-S67.

26. Marmur ES, Phelps R, Goldberg DJ (2004) Clinical, histologic and electron microscopic findings after injection of a calciumhydroxylapatite filler. J Cosmet Laser Ther 6: 223-226.

27. Zerbinati N, Calligaro A (2018) Calcium hydroxylapatite treatment of human skin: evidence of collagen turnover through picrosirius red staining and circularly polarized microscopy. Clin Cosmet Investig Dermatol 11: 29-35. 
28. Lacombe V (2009) Sculptra: a stimulatory filler. Facial Plast Surg 25: 95-99.

29. Lorenc ZP (2012) Techniques for the optimization of facial and nonfacialvolumization with injectable poly-I-lactic acid. Aesthetic Plast Surg 36: 1222-1229.

30. Butterwick K, Lower NJ (2009) Injectable poly-L-lactic acid for cosmetic enhancement: learning from the European experience. $J$ Am Acad Dermatol 61: 281-293.

31. Levy RM, Redbord KP, Hanke CW (2008) Treatment of HIV lipoatrophy and lipoatrophy of aging with poly-L-lactic acid: a prospective 3-year follow-up study. J Am Acad Dermatol 59: 923-933.

32. Lowe NJ, Mazwell, CA, Lowe P, Shah A, Patnaik R (2009) Injectable poly-l-lactic acid: 3 years of aesthetic experience. Dermatol Surg 35 Suppl 1: 344-349.

33. Gogolweskin S, Jovanovic M, Perren SM, Dilton JG, Hughes MK (1993) Tissue response and in vivo degradation of selected polyhydroxyacids: polylactides (PLA), poly(3-hydroxybutyrate) (PHB), and poly(3-hydroxybutyrate-co-3-hydroxyvalerate) (PHB/VA). J Biomed Mater Res 27: 1135-1148.
34. Vleggar D (2005) Facial volumetric correction with injectable poly-Llactic acid. Dermatol Surg 31: 1511-1517.

35. Narins RS, Baumann L, Brandt FS, Fagien S, Glazer S, et al. (2010) A randomized study of the efficacy and safety of injectable poly-Llactic acid versus human-based collagen implant in the treatment of nasolabial fold wrinkles. J Am Acad Dermatol 62: 448-462.

36. Lowe P, Lowe N, Patnaik R (2011) Three-dimensional digital surface imaging measurement of the volumizing effect of injectable poly-Llactic acid for nasolabial folds. J Cosmet Laser Ther 13: 87-94.

37. Lin J, Shi Y, Men Y, Wang X, Ye J, et al. (2020) Mechanical Roles in Formation of Oriented Collagen Fibers. Tissue engineering part B: Reviews 26: 2. 